\title{
The rare rhinoceros beetle, Ceratophileurus lemoulti Ohaus, 1911 , in French Guiana and Suriname (Coleoptera, Scarabaeidae, Dynastinae, Phileurini)
}

\author{
Conrad P.D.T. Gillett', Alain Drumont ${ }^{2}$, Yannig Ponchel ${ }^{3}$ \\ I Nationale Zoölogische Collectie van Suriname, Anton de Kom Universiteit van Suriname, Postbus 9212, Pa- \\ ramaribo, Suriname 2 Institut royal des Sciences naturelles de Belgique, département d'entomologie, rue Vautier \\ 29, B-1000 Bruxelles, Belgium 311 rue Auguste Renoir, F-97310 Kourou, Guyane, France
}

Corresponding author: Conrad P.D.T. Gillett (conradgillett@hotmail.com)

Academic editor: Brett Ratcliffe | Received 20 July 2009 | Accepted 10 November 2009 | Published 28 January 2010

Citation: Gillett CPDT, Drumont A, Ponchel Y (2010) The rare rhinoceros beetle, Ceratophileurus lemoulti Ohaus, 1911, in French Guiana and Suriname (Coleoptera, Scarabaeidae, Dynastinae, Phileurini). In: Ratcliffe B, Krell F-T (Eds) Current advances in Scarabaeoidea research. ZooKeys 34: 193-198. doi: 10.3897/zookeys.34.240

\section{Abstract}

The rare dynastine, Ceratophileurus lemoulti Ohaus, 1911, previously known only from French Guiana, is here reported for the first time from Suriname. All biological, distributional and temporal data available for the species in both territories are presented and discussed.

\section{Keywords}

Ceratophileurus lemoulti, Dynastinae, Phileurini, scarab beetle, Suriname, French Guiana, new country record, distribution

\section{Introduction}

The tribe Phileurini belongs to the scarab beetle subfamily Dynastinae (commonly called rhinoceros beetles) and contains approximately 225 described species in 36 genera. It is worldwide in distribution. Tropical regions have the most diverse fauna of these beetles, especially in the New World, which has the highest species richness; more than half of all known species occur there (Ratcliffe and Cave 2006). The beetles be- 
longing to this tribe are easily recognised by the enlarged mentum that covers the base of the labial palpi. In the New World, all species are black, flattened beetles, usually having the elytral striae clearly visible. They are nocturnally active and are attracted to artificial light, where they are often collected, although they are also found in decaying trunks and logs, where presumably the majority of species undertake their larval development. Some species have been associated with the nests of termites or ants (Ratcliffe and Cave 2006). Most adult Phileurini do not exhibit distinctive sexual dimorphism or obvious secondary sexual characters as is common in many other Dynastinae, although some do possess horns and other protuberances on the head and/or pronotum. One such species is Ceratophileurus lemoulti Ohaus.

The genus Ceratophileurus contains only the species, C. lemoulti, described from the French overseas Département of Guyane (French Guiana) and which has, until now, been recorded only rarely from that territory. French Guiana has a rich diversity of Dynastinae, with no fewer than 138 species, including 35 species of Phileurini, recorded from there (Ponchel, unpublished data). The diversity of Dynastinae in neighbouring Suriname is much less known, with few species recorded in the literature and only about 30 species presently represented in the National Zoological Collections of Suriname (Gillett, personal observation), including four species of Phileurini. French Guiana, Suriname and Guyana (the Guianas) have mostly escaped large-scale human induced alteration of their natural habitats, and consequently still contain vast areas of pristine Amazonian rainforest.

Ceratophileurus lemoulti is a distinctive species of Phileurini that can be easily identified with the keys of Endrödi $(1977,1985)$. The most striking character is the long, recurved and acuminate horn arising from the frons, which is present in both sexes. The pronotum of major specimens also bears on each side a short, laterally compressed projection, which is truncate apically (Figs 1-2). It is difficult to separate the sexes based on external morphology alone; the only reliable method is to dissect the abdomen to look for the sclerotised parameres found in the male. Thouvenot (2007) indicated that the only external difference between the single male specimen he studied and female specimens was the reduced size of the male. However our data indicate that this is not a reliable character, because female specimens we examined fell within the size range of the few males available for study. This paper aims to summarise and consolidate all known biological and distributional data available for $C$. lemoulti.

\section{Materials and methods}

Specimens of $C$. lemoulti were studied from several institutional and private collections. The label data are reproduced below. Collection repositories are indicated by the following acronyms:
ADC
Alain Drumont Collection, Bruxelles, Belgium
GSC
Guy Silvestre Collection, Bédoin, France
IRSNB Institut royal des Sciences naturelles de Belgique, Bruxelles, Belgium 


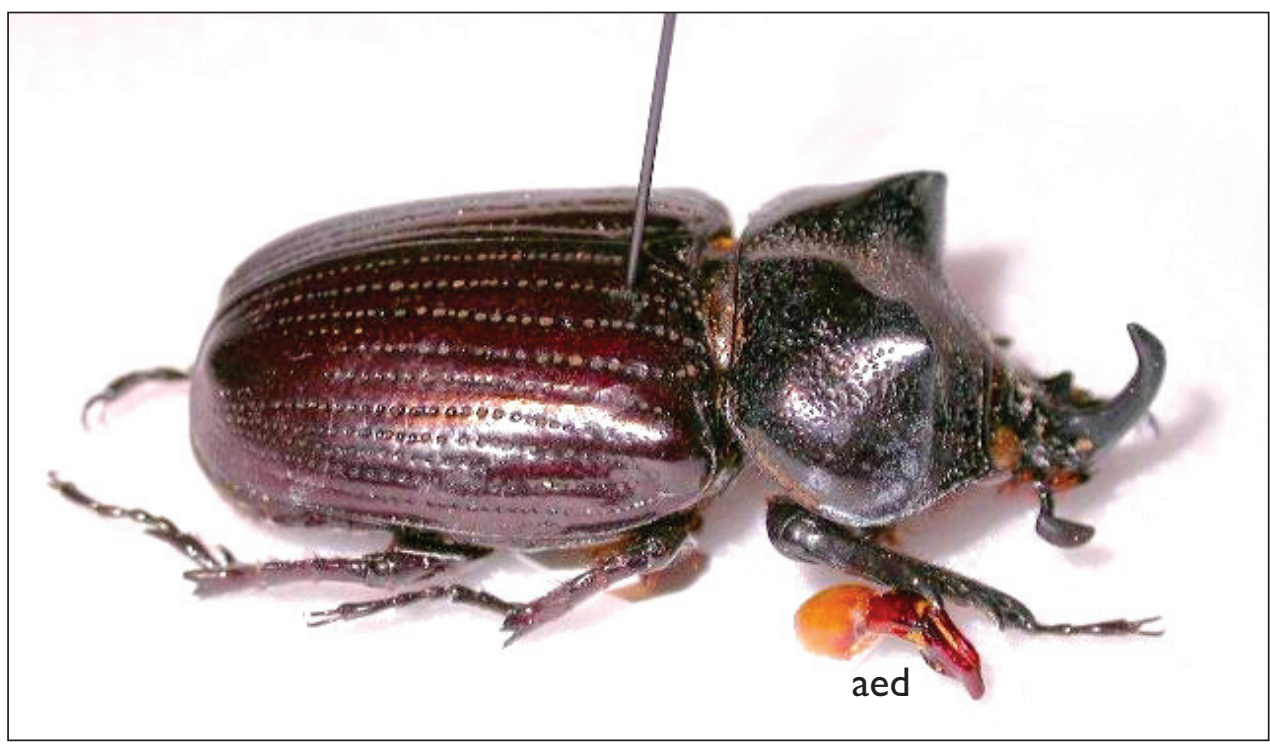

Figure I. Male specimen of Ceratophileurus lemoulti Ohaus collected in French Guiana (YPC). Photograph by Yannig Ponchel. Aedeagus (aed) attached to card mount underneath specimen, in oblique view.

RPDC Roger-Paul Dechambre Collection, Paris, France

YPC Yannig Ponchel Collection, Kourou, Guyane, France

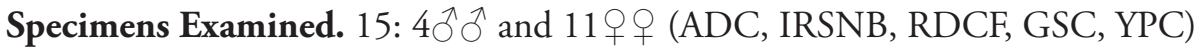

French Guiana (France, Département outre mer de la Guyane). St-Laurent-duMaroni, V.1980, 1 male (RPDC); Crique Nancibo, VI.1987, 1 female (RPDC); No data, 1 female (RPDC); Cacao, no date, 1 female (RPDC); Piste Coralie, IV.1989, 1 female (RPDC); Route de Régina, PK 35, 05.XI.1989, 1 female (GSC); Piste FRG, 09.V.1997, 1 male (YPC); Piste de Coralie, PK 2, V.1999, 1 female (YPC); Piste de Patagaïe, PK 27, VIII.2000, 1 female (YPC); Piste de Bélizon, PK 12-16.II.2001, 1 male (YPC;specimen shown in Fig. 1); Route de Petit Saut, PK 9, II.2000, 1 female (YPC); Cacao, VII.2000, 1 female (YPC); Cacao, V.2001, 1 female (YPC); RN 1, PK 20.IX.2000, 1 female (IRSNB).

Suriname. Sipaliwini, Central Suriname Nature Reserve, Raleighvallen, 14-16-II2000, 1 male (Fig. 2), new country record.

Collecting localities for specimens examined are in Fig. 3.

Literature Records. Ohaus (1911) - French Guiana: St-Laurent-du-Maroni (Type locality); Blackwelder (1944) - French Guiana; Endrödi (1977) - French Guiana: StLaurent-du-Maroni; Endrödi (1985) - French Guiana; Lachaume (1992) - French Guiana; Thouvenot (2007) - French Guiana: Petit Saut, PK 18 + PK 3, 15.VII.1993; Route Nationale 2, PK 79, 12.V.1997.

Temporal data. February (2), April (1), May (5), June (1), July (2), August (1), September (2), November (1) 


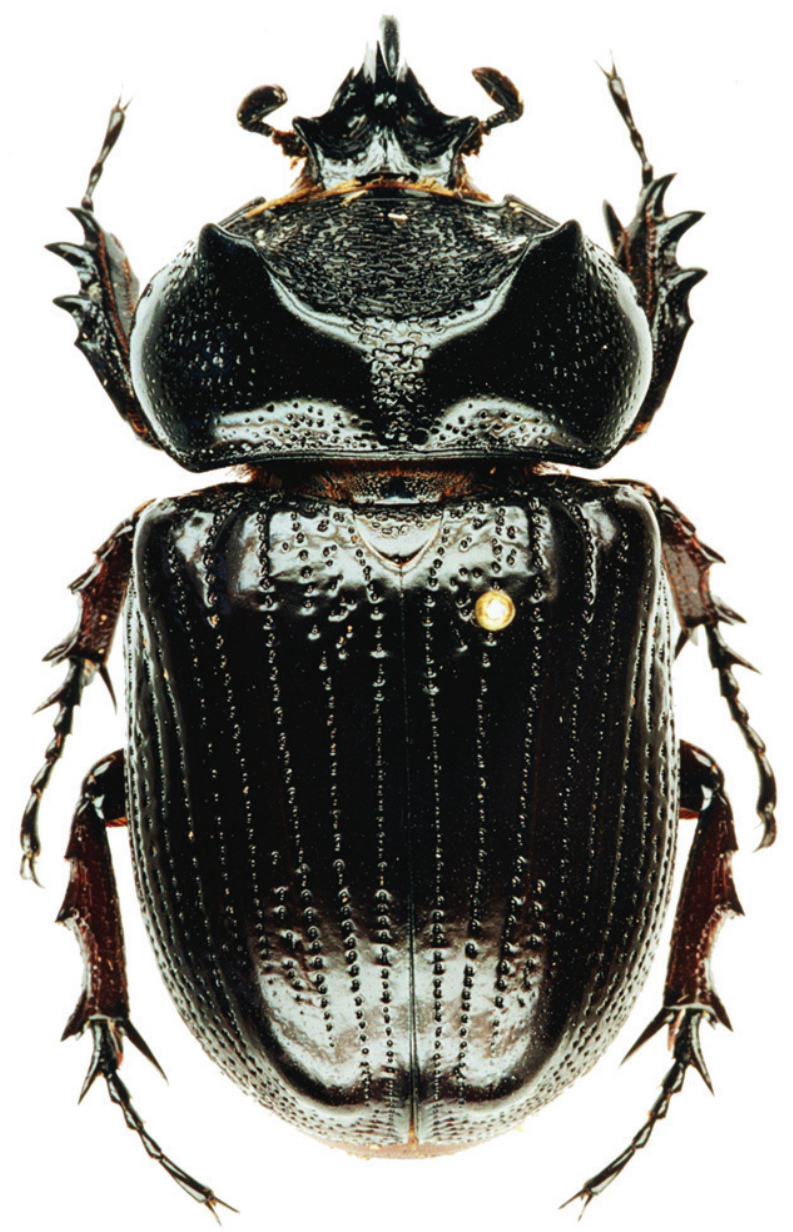

Figure 2. Male specimen of Ceratophileurus lemoulti Ohaus collected at Raleighvallen, Suriname. Photograph by Alain and Marcel Galant.

\section{Discussion}

C. lemoulti is a rare species. The holotype was collected by E. Le Moult at St-Laurent-du-Maroni, French Guiana. Since its description, few other records have been published. It appears that the males are particularly scarce in collections; Thouvenot (2007) was able to collect only three females in more than 20 years of collecting in French Guiana. Of the 15 specimens we were able to study, only four were males. Whether males are truly less abundant or are less easily attracted to lights remains to be determined. 


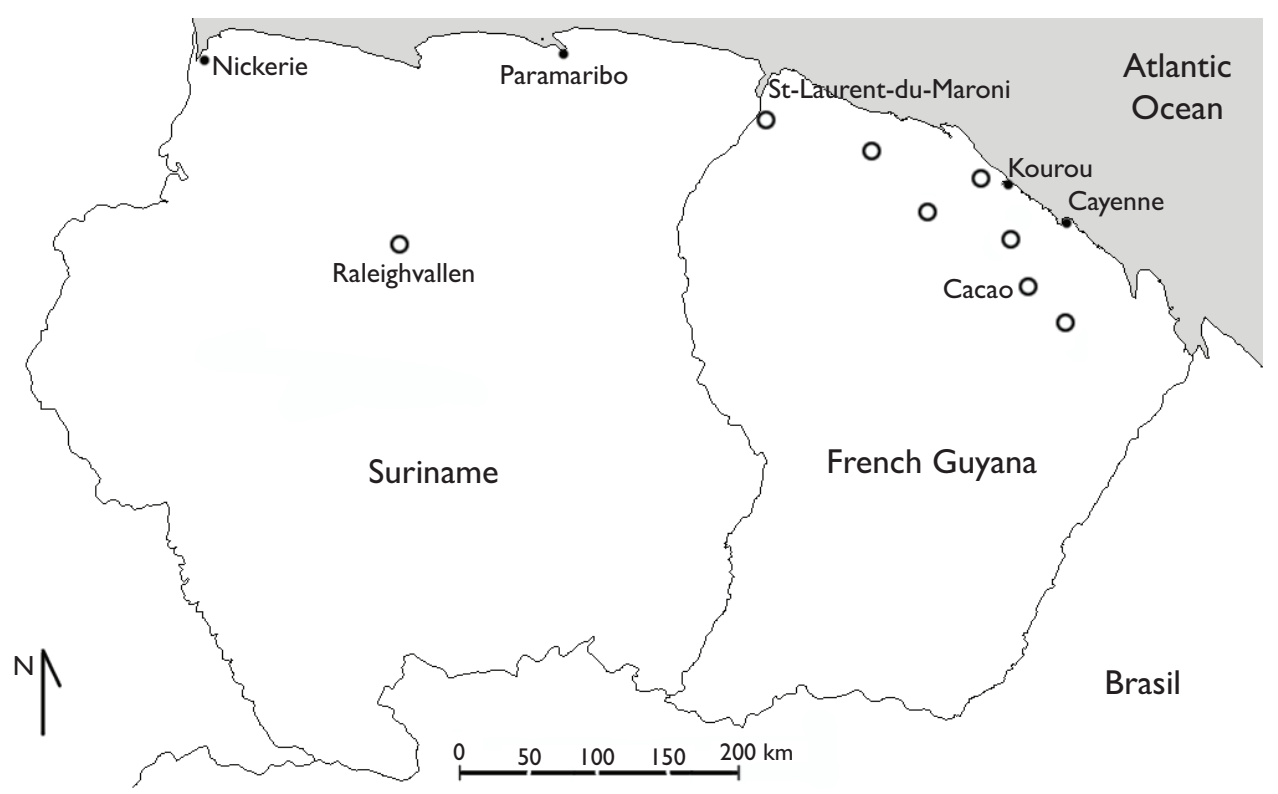

Figure 3. Distribution map for Ceratophileurus lemoulti Ohaus. Collection localities in black circles.

The possession of well developed horns in box sexes is exceptional within the Scarabaeoidea; usually only the male is armed. This condition is also seen in species of Megaphanaeus (Scarabaeinae: Phanaeini), which also exhibit little sexual dimorphism, but in which both sexes possess well developed cephalic and pronotal horns.

Although the species has been collected during different months, the temporal data indicates a peak activity in May, which represents approximately the onset of the main rainy season in the Guyanas (lasting until August). Many adult Dynastinae are known to be most abundant during the beginning of rainy seasons across the Neotropics (e.g., Ratcliffe 2003; Gillett and Ponchel, personal observations). Equally interesting is the lack of captures during the months of December and January, which approximately coincides with the start of the short rainy season in the Guianas. This is a period of known activity for many Coleoptera and it may be significant that it has not been collected during those months.

As far as is known, all the specimens examined for this paper were collected at artificial light (especially mercury vapour light traps) in areas of primary or secondary lowland Amazonian rainforest. The species has usually been collected between the hours of 19:00 and 22:00, as is common for many Dynastinae (Ponchel, personal observation). In French Guiana its distribution is scattered, but most localities occur along the north of the territory (Fig. 3). However, because access to the remote forested interior of the Département is usually difficult, there is a good possibility that this species is also present there.

No other biological information is available, and the immature stages remain completely unknown. It appears that this species is an endemic and enigmatic element of the fauna of the Guianan shield. 
The single male specimen collected at Raleighvallen in the Central Suriname Nature Reserve is the only specimen recorded to date from Suriname. Raleighvallen is an area of pristine lowland Amazonian rainforest, renowned for its rich biodiversity that remains virtually unknown entomologically. This record represents a modest range extension for the species, increasing its distribution by some $250 \mathrm{~km}$ to the west of the westernmost locality in French Guiana.

\section{Acknowledgements}

We express our deep gratitude to Roger-Paul Dechambre (France) and to Guy Silvestre (France) for generously sharing their important specimens and data with us. We would like to especially thank Marc and Léticia Stalmans for sharing the results of their collecting in Suriname. We are also indebted to Alain and Marcel Galant (Belgium) for the habitus photograph of the specimen, to Paul Schoolmeesters (Belgium) for his continued assistance in locating literature, and to two anonymous reviewers for their constructive comments.

\section{References}

Blackwelder RE (1944) Checklist of the coleopterous Insects of Mexico, Central America, the West Indies and South America. U. S. National Museum Bulletin 185 (2): 220-265.

Endrödi, S. 1977. Monographie der Dynastinae 8. Tribus: Phileurini, amerikanische Arten I. (Coleoptera). Folia Entomologica Hungarica 30 (1): 7-45.

Endrödi S (1985) The Dynastinae of the World. Dr W. Junk, Dordrecht, Netherlands. 800 pp., 46 plates.

Lachaume G (1992) Dynastidae Américains. Cyclocephalini-Agaocephalini-PentodontiniOryctini-Phileurini. Les Coléoptères du Monde 14. Sciences Nat, Venette, France. Pp. 56, 83-89, plates $1-11$.

Ohaus F (1911) Neue Gattungen und Arten der Dynastidengruppe Phileurini. Entomologische Rundschau 28 (22):169-171.

Ratcliffe BC (2003) The dynastine scarab beetles of Costa Rica and Panama. Bulletin of the University of Nebraska State Museum 16: 1-506.

Ratcliffe BC, Cave R (2006) The dynastine scarab beetles of Honduras, Nicaragua, and El Salvador. Bulletin of the University of Nebraska State Museum 21: 1-424.

Thouvenot M (2007) Enfin un male de Ceratophileurus lemoulti Ohaus, 1911. L'Entomologiste 63 (2): 81-82. 